\title{
SANITASI KAPAL PADA KMP LEGUNDI DI WILAYAH KERJA KANTOR KESEHATAN PELABUHAN KELAS I SURABAYA
}

Kelara Dyah Arintia Putri, Bambang Sunarko, Fitri Rokhmalia*

Jurusan Kesehatan Lingkungan Poltekkes Kemenkes Surabaya

*Email korespondensi: fitrikhaizuran@gmail.com

\begin{abstract}
ABSTRAK
Penyehatan kapal penumpang perlu dilakukan dalam rangka mewujudkan sanitasi kapal yang baik. Pemenuhuan syarat sanitasi pada kapal agar terciptanya kenyamanan dan pencegahan penularan penyakit bagi penumpang dan ABK. Penelitian ini bertujuan untuk menggambarkan sanitasi kapal penumpang di wilayah kerja KKP Kelas I Surabaya.

Penelitian ini bersifat observasi deskriptif dengan pendekatan cross sectional, penentuan objek penelitian yaitu semua kapal penumpang yang berlabuh/sandar di pelabuhan selama waktu penelitian. Penilaian sub variabel yakni dapur, ruang rakit makanan, ruang tidur ABK, air minum, limbah cair, limbah medis/padat dan keberadaan vektor terdiri dari dua kategori yaitu memenuhi syarat dan tidak memenuhi syarat. Seluruh variabel akan disajikan dalam bentuk tabel.

Hasil penelitian menunjukkan bahwa penilaian terhadap variabel sanitasi dapur, ruang rakit makanan, ruang tidur $A B K$, air minum dan keberadaan vektor 2 ruangan (33\%) terlihatnya tanda keberadaan vektor dan 4 ruangan (67\%) tidak terlihat adanya keberadaan vektor pada KMP Legundi dikategorikan memenuhi syarat, sedangkan variabel limbah cair dan limbah medis/padat tidak memenuhi syarat.

Disimpulkan dari sanitasi dapur, ruang rakit makanan, ruang tidur $A B K$, air minum dan keberadaan vektor pada KMP Legundi dikategorikan memenuhi syarat, sedangkan variabel limbah cair dan limbah medis/padat tidak memenuhi syarat. Disarankan perlu mempertahankan sistem pemeriksaan sanitasi kapal, serta diperlukannya pemantauan yang dilakukan secara berkala agar tidak menjadi tempat penyebaran penyakit. Serta memberi himbauan untuk melakukan pengolahan limbah cair yang dihasilkan dari kegiatan kapal sebelum dibuang, memberi himbauan kepada pemilik kapal maupun ABK untuk selalu menjaga kebersihan kapal dan meningkatkan kuantitas maupun kualitas fasilitas agar penumpang menjadi nyaman.
\end{abstract}

Kata kunci: Sanitasi kapal, Kapal Penumpang

\section{PENDAHULUAN}

Kapal berdasarkan International Health Regulations (IHR 2005), merupakan alat angkut penumpang maupun barang yang dapat berlayar menggunakan mesin atau layar yang melakukan perjalanan nasional maupun internasional. Berdasarkan Permenkes Republik Indonesia No. 40 tahun 2015 tindakan sanitasi kapal merupakan usaha penyehatan, pengamanan dan pengendalian yang ditujukan terhadap pemeriksaan faktor risiko pada kapal untuk mencegah penularan penyakit melalui desinfeksi, dekontaminasi, dan deratisasi. Pemeriksaan sanitasi dilakukan pada seluruh ruang pada kapal yakni dapur, gudang, ruang tidur, penyediaan air bersih, limbah cair, sampah padat, kamar mesin dan area lain yang perlu diperiksa.

\begin{abstract}
Sanitasi kapal berlaku untuk semua jenis kapal baik kapal penumpang, maupun kapal barang. Pemeriksaan sanitasi kapal dimaksudkan untuk pengeluaran sertifikat sanitasi guna memperoleh Surat Izin Kesehatan Berlayar (SIKB). Hasil pemeriksaan dinyatakan berisiko tinggi atau risiko rendah, jika kapal yang diperiksa dinyatakan risiko tinggi maka diterbitkan Ship Sanitation Control Certificate (SSCC) setelah dilakukan tindakan sanitasi, apabila faktor risiko rendah diterbitkan Ship Sanitation Exemption Control Certificate (SSCEC), dan pemeriksaan dilakukan dalam masa waktu enam bulan sekali. pemeriksaan sanitasi kapal menjadi agenda rutin dan tugas penting bagi KKP sehingga kapal-kapal yang bersandar di seluruh pelabuhan di Indonesia terjamin sanitasi kapalnya dan
\end{abstract}


bebas dari sumber penularan penyakit. Adapun faktor-faktor yang dinilai berkaitan dengan sanitasi kapal antara lain adalah faktor internal seperti perilaku Anak Buah Kapal (ABK), kepemimpinan Nakhoda, dan kejelasan Standard Operational Procedure (SOP) sanitasi kapal. Faktor eksternal seperti kebijakan dan pengawasan dari KKP. Beberapa penelitian mengemukakan faktor-faktor tersebut mempunyai kaitan dengan tingkat sanitasi kapal (Saifullah, 2010).

$$
\text { Pelaksanaan inspeksi dan }
$$

penilaian sanitasi kapal dapat berpengaruh terhadap hasil inspeksi. Petugas inspeksi, instrumen yang digunakan, waktu pelaksanaan inspeksi, standart operasional inspeksi dan kondisi lapangan saat inspeksi merupakan beberapa hal yang dapat mempengaruhi proses pelaksanaan inspeksi sanitasi kapal yang dilakukan. Pada pelaksanaan inspeksi ini terdapat suatu kendala wabah penyakit yakni pandemi COVID-19 yang melanda Indonesia, sehingga dalam penelitian ini hanya diperoleh 1 sampel kapal dari 12 kapal yang bersandar pada bulan februari.

Hasil penelitian berdasarkan data penilaian sanitasi kapal pada tahun 2016 di pelabuhan Tanjung Perak Surabaya sebesar $91,67 \%$ ditemukan adanya kecoa dengan kategori tinggi serta rendahnya personal higiene penjamah makanan (Harahap, 2016). Hasil penelitian pada tahun 2017 meliputi sanitasi dapur, sanitasi ruang penyimpanan makanan dan sanitasi makanan sebagian besar mempunyai risiko sanitasi yang rendah (Mutiarani, 2017). Hasil penelitian pada tahun 2019 menunjukkan 92,9\% higiene tempat pengolahan makanan tidak baik (Sanila, 2019). Tujuan penelitian ini adalah menggambarkan sanitasi kapal penumpang di wilayah kerja KKP Kelas I Surabaya.

\section{METODE PENELITIAN}

Jenis penelitian ini merupakan penelitian observasional deskriptif serta menggunakan studi literatur yang berkaitan dengan tujuan untuk menggambarkan sanitasi kapal penumpang di wilayah kerja Kantor Kesehatan Pelabuhan Kelas I Surabaya. Populasi dalam penelitian ini adalah seluruh kapal yang bersandar di wilayah kerja Kantor Kesehatan Pelabuhan kelas I Surabaya selama bulan Februari 2020. Pengambilan sampel secara cross sectional diambil dengan teknik accidental random sampling, dimana pengambil sampel dilakukan pada suatu kebetulan ada atau tersedia pada lokasi penelitian.

Variabel bebas dalam penelitian ini sanitasi dapur, ruang rakit makanan, ruang tidur $A B K$, sanitasi air minum, limbah cair serta limbah medis/padat dan keberadaan vektor. Variabel terikat pada penelitian ini adalah sanitasi kapal penumpang.

Data yang telah terkumpul dengan lembar observasi dengan kriteria penilaian baik, cukup dan kurang, dilengkapi, diolah, disusun dan kemudian di tabulasi serta dianalisis secara deskriptif berdasarkan Permenkes RI No. 40 Tahun 2015 Tentang Sertifikat Sanitasi Kapal.

\section{HASIL DAN PEMBAHASAN}

Pada penelitian yang dilakukan terkait sanitasi kapal pada kmp legundi di wilayah kerja kantor kesehatan pelabuhan kelas I Surabaya, dengan hasil sebagai berikut :

\section{Tabel 1}

HASIL PENILAIAN SANITASI KAPAL

\begin{tabular}{lccc}
\hline Jenis Variabel Sanitasi Kapal & Nilai & Nilai Max & Presentase (\%) \\
\hline Dapur (Galley) & 40 & 40 & $100 \%$ \\
\hline Ruang Rakit Makanan (Pantry) & 30 & 30 & $100 \%$ \\
\hline Ruang Tidur ABK/Crew & 60 & 60 & $100 \%$ \\
\hline Air Minum (Portable Water) & 20 & 20 & $100 \%$ \\
\hline Limbah Cair (Sewage) & 10 & 20 & $50 \%$ \\
\hline Limbah Medis Padat (Medic/Solid Waste) & 10 & 30 & $30 \%$ \\
\hline Keberadaan Vektor & 40 & 60 & $60 \%$ \\
\hline JUMLAH & 210 & 260 & $81 \%$ \\
\hline
\end{tabular}


Berdasarkan Tabel 1 Pada penelitian yang dilakukan terkait sanitasi kapal pada kmp legundi di wilayah kerja kantor kesehatan pelabuhan kelas I Surabaya yaitu pada penilaian sanitasi pada variabel dapur (Galley) dengan nilai 40 dan prosentase 100, ruang rakit makanan (Pantry) dengan nilai 30 dan prosentase $100 \%$, ruang tidur $\mathrm{ABK} / \mathrm{Crew}$ dengan nilai 60 dan prosentase $100 \%$, air minum (Portable Water) dengan nilai 20 dan prosentase $100 \%$, imbah cair (Sewage) dengan nilai 10 dan prosentase $50 \%$, limbah medis padat (Medic/Solid Waste) dengan nilai 10 dan prosentase $20 \%$, Keberadaan Vektor dengan nilai 40 dan prosentase $30 \%$.

Hasil penilaian variabel dapur memenuhi syarat Keadaan dapur kapal dilihat dari tingkat kebersihan dapur, ada tidaknya sirkulasi udara, pencahayaan yang cukup, adanya tempat pencucian piring dan peralatan dapur lain yang saniter, dan tidak ada tanda-tanda kehidupan vektor atau rodent. Tetapi pada tempat pencucian tangan tidak adanya tisu kering, sehingga perlu tersedianya tempat cuci tangan yang saniter yaitu dengan penambahan sabun dan tisu pengering. Dapur yang tidak di bersihkan menggunkan desinfektan membuat dapur tidak bersih secara sempurna, sisa makanan setelah masak disekitar dapur yang dapat menjadi sumber makanan dapat mengundang tikus (Gita et.al, 2017).

Varibel Ruang Rakit Makanan kmasuk dalam kategori memenuhi syarat, Telah dilakukan pemisahan peralatan serta pemisahan tempat penyimpanan antara bahan dan makanan siap saji, dan makanan yang langsung disajikan setelah masak sehingga tidak disimpan dalam waktu lama. Penjamah makanan pada KMP Legundi saat bersin/batuk tidak menutup mulut dengan tisu/sapu tangan Sejalan dengan penelitian Aqso (2016) menunjukkan bahwa sebesar $86,67 \%$ kapal motor telah menerapkan cara penyimpanan makanan yang baik, dengan memisahkan antara makanan kering dan basah guna menjaga kualitas ataupun mutu makanan, sebesar 70,00\% hasil observasi tempat penyiapan makanan atau pantry dalam kondisi bersih, sehingga dapat mendukung kondisi sanitasi kapal yang memenuhi syarat kesehatan atau memiliki risiko rendah terhadap penularan penyakit. Hasil penilaian lain menunjukkan bahwa sebesar 20,00\% kapal motor yang cara penyiapan makanan memenuhi persyaratan, kondisi tersebut dilihat dari kuku tangan yang tidak panjang, memakai celemek pada saat memasak, dan mencuci tangan sebelum dan sesudah menjamah makanan serta hasil wawancara diperoleh sebesar 96,67\% waktu penyajian makanan tidak lebih dari 4 jam setelah dimasak atau dihidangkan.

Variabel ruang tidur $\mathrm{ABK} / \mathrm{Crew}$ dengan nilai 60 dan prosentase $100 \%$, yakni telah memenuhi syarat yang sesuai dengan Peraturan Pemerintah no 7 Tahun 2000 tentang Kepelautan mensyaratkan kamar tidur harus disekat dari cuaca panas dan dingin serta kebisingan, kedap air, dan gas, tidak memiliki pintu langsung ke ruang muatan, dapat mencegah masuknya serangga melalui pintu, tetap terawat dan dijaga dalam keadaan bersih dan tidak boleh diisi dan digunakan menyimpan barang lainnya, memiliki luas lantai kamar tidur cukup untuk tiap anak buah kapal. Sejalan dengan penelitian Besse (2011) bahwa dari 13 unit kapal penumpang yang telah diinspeksi terdapat 3 unit kapal penumpang yang memiliki kamar ABK (Anak Buah Kapal) dengan 3 (75\%) komponen yang memenuhi syarat yaitu ventilasi cukup, penerangan cukup, dan tidak ditemukan serangga dan 1 (25\%) komponen yang tidak memenuhi syarat yaitu kotor sedangkan 10 unit kapal penumpang lainnya memiliki kamar ABK (Anak Buah Kapal) yang telah memenuhi syarat yaitu terpenuhinya $4(100 \%)$ komponen aspek sanitasi. Kamar ABK (Anak buah kapal) rata-rata telah memenuhi persyaratan karena kapasitas tempat tidur dalam kamar sama dengan kamar penumpang untuk kelas I, II, dan III. Hal ini disebabkan kapasitas kamar tidur yang disediakan hanya terdiri dari empat, tiga, dua bahkan satu tempat tidur dalam tiap kamar sehingga memberikan kontrol 
yang lebih mudah dalam penanganan masalah kebersihan.

Hasil penilaian pada variabel air minum (Portable Water) dengan nilai 20 dan prosentase $100 \%$, masuk dalam kategori memenuhi syarat dengan kondisi air yang memenuhi persyaratan fisik (tidak berasa, tidak berbau dan tidak berwarna) dan tersedianya air yang cukup untuk memenuhi setiap kegiatan. Ditinjau dari ilmu kesehatan masyarakat, penyediaan air bersih harus memenuhi kebutuhan dan sesuai syarat yang berlaku sehingga dapat mencegah timbulnya penyakit di masyarakat. Berdasarkan Permenkes RI nomor 492 tahun 2010 untuk menjaga kualitas air minum yang dikonsumsi masyaratakat, dilakukan pengawasan kualitas air minum secara eksternal dan secara internal. Pengawasan secara eksternal dilakukan oleh Dinas Kesehatan Kabupaten/Kota atau oleh KKP khusus untuk wilayah KKP. Kegiatan pengawasan kualitas air minum meliputi inspeksi sanitasi, pengambilan sampel air, pengujian kualitas air, analisis hasil pemeriksaan laboratorium, rekomendasi dan tindak lanjut. Pihak KKP telah rutin melakukan pemeriksaan kualitas air minum, sehingga dijamin keamanan air minum untuk dikonsumsi.

Hasil penilaian sanitasi limbah cair pada KMP Legundi yakni tidak memenuhi syarat karena tidak adanya pengolahan limbah cair sebelum dibuang, tetapi saluran pembuangan dalam keadaan tertutup sehingga tidak menimbulkan bau. Sesuai dengan Peraturan Menteri Negara Lingkungan Hidup Nomor 03 tahun 2007 pada pasal 2 menyebutkan bahwa "Setiap pemilik dan/atau operator kapal dilarang melakukan pembuangan limbah bahan berbahaya dan beracun ke media lingkungan hidup". Pasal 3 ayat ke (2) menyebutkan bahwa "pemilik dan/atau operator kapal dapat menyerahkan limbah bahan berbahaya dan beracun dari kegiatan kapalnya kepada penanggung jawab usaha dan/atau kegiatan fasilitas pengumpulan dan penyimpanan limbah bahan berbahaya dan beracun". Sehingga setiap kapal yang berlayar di perairan Indonesia wajib mengelola limbahnya dengan menyerahkan kepada fasilitas pengumpulan dan penyimpanan limbah berbahaya dan beracun di setiap pelabuhan umum maupun pelabuhan khusus. Sejalan dengan penelitian Aqso (2016) sebesar 70,00\% sarana pembuangan limbah cair memenuhi syarat (sarana berupa saluran tertutup, tidak bocor dan dialirkan ke tempat khusus) dan bebas dari serangga, namun dari semua kapal yang diperiksa tidak dilakukan pengolahan limbah cair sebelum dibuang ke lingkungan sesuai dengan Peraturan Menteri Negara Lingkungan Hidup Nomor 03 tahun 2007. Hasil penilaian variabel limbah medis/padat (Medic/Solid Waste) masuk dalam kategori memenuhi syarat karena tidak adanya pemisahan sampah sesuai jenisnya sehingga dikumpulkan dalam 1 tempat dengan bahan yang kuat, anti karat dan tertutup tetapi terdapat beberapa sampah yang masih berserakan. Untuk limbah medis yang dihasilkan perlu dilakukan pengolahan sesuai dengan Peraturan Menteri Negara Lingkungan Hidup Nomor 03 tahun 2007 pada pasal 2 menyebutkan bahwa "setiap pemilik dan/atau operator kapal dilarang melakukan pembuangan limbah bahan berbahaya dan beracun ke media lingkungan hidup". Pasal 3 ayat ke (2) menyebutkan bahwa "pemilik dan/atau operator kapal dapat menyerahkan limbah bahan berbahaya dan beracun dari kegiatan kapalnya kepada penanggung jawab usaha dan/atau kegiatan fasilitas pengumpulan dan penyimpanan limbah bahan berbahaya dan beracun". Sehingga setiap pelabuhan umum dan pelabuhan khusus diwajibkan menyediakan fasilitas pengumpulan, penyimpanan dan pengolahan limbah yang berasal dari kegiatan kapal.

Berdasarkan hasil penelitian Aqso (2016) menunjukkan bahwa sebesar $76,67 \%$ hasil penilaian sanitasi dapur/galley tidak dilengkapi dengan tempat sampah dari bahan kedap air dan berpenutup serta cucian piring kotor yang tidak langsung dicuci dan dibiarkan satu malam, dan banyaknya sisa makanan yang berceceran dapat memengaruhi tingginya kepadatan kecoa. Pemeriksaan sanitasi memiliki 
risiko kesehatan tinggi terhadap penularan penyakit karena tidak dilengkapinya tempat sampah berpenutup pada beberapa bagian di atas kapal khususnya pada bagian dapur, sehingga berpotensi menjadi tempat perkembangbiakan bagi vektor kecoa

Hasil penilaian pada variabel keberadaan vektor di KMP Legundi, berdasarkan Permenkes No. 50 tahun 2017 vektor adalah artropoda yang dapat menularkan, memindahkan, dan/atau menjadi sumber penular penyakit. Binatang Pembawa Penyakit adalah binatang selain artropoda yang dapat menularkan, memindahkan, dan/atau menjadi sumber penular penyakit.Pengendalian Vektor dan Binatang Pembawa Penyakit meliputi kegiatan: pengamatan dan penyelidikan Bioekologi, penentuan status kevektoran, status resistensi, dan efikasi, serta pemeriksaan sampel; Pengendalian Vektor dan Binatang Pembawa Penyakit dengan metode fisik, biologi, kimia, dan pengelolaan lingkungan; Pengendalian terpadu terhadap Vektor dan Binatang Pembawa Penyakit. Penilaian keberadaan vektor KMP Legundi yakni dengan 2 ruangan terlihatnya tanda keberadaan vektor dan 4 ruangan tidak terlihat adanya keberadaan vektor, sehingga keberadaan vektor telah memenuhi syarat. Pada dapur dan limbah padat ditemukaannya celah-celah yang kotor seperti pada celah bawah peralatan dapur ditemukaannya tumpukantumpukan sisa makanan dan berserakannya sampah sehingga memungkinkan menjadi tempat berkembangbiaknya vektor penyakit, sehingga keberadaan vektor telaha memenuhi syarat. Berdasarkan hasil penelitian Gita et.al (2017) menunjukkan bahwa Kapal yang memiliki kondisi sanitasi kapal yang memenuhi syarat sebanyak 26 kapal dengan persentase $70,3 \%$ dan kapal yang meiliki kondisi sanitasi yang tidak memenuhi syarat sebanyak 11 kapal dengan persentase $29,7 \%$ tidak sepenuhnya bebas dari risiko di temukan tanda - tanda keberadaan tikus dan keberadaan tikus. Hal ini menunjukkan > $50 \%$ kapal yang diperiksa memiliki kondisi sanitasi kapal yang memenuhi syarat. akan tetapi, kapal yang telah memenuhi syarat tidak sepenuhnya bebas dari risiko di temukan tanda - tanda keberadaan tikus dan keberadaan tikus. Masih didapatkan ruang - ruang yang belum memenuhi persyaratan sanitasi kapal dan berpotensi mengundang tikus yang dapat menjadi sumber makanan dan tempat perkembangbiakan tikus.

\section{KESIMPULAN}

1. Sanitasi dapur pada KMP Legundi keseluruhan telah memenuhi syarat, tetapi pada tempat pencucian tangan tidak adanya tisu kering

2. Sanitasi ruang rakit makanan pada KMP Legundi keseluruhan telah memenuhi syarat, telah dilakukan pemisahan peralatan, pemisahan tempat penyimpanan antara bahan dan makanan siap saji, dan makanan yang langsung disajikan setelah masak sehingga tidak disimpan dalam waktu lama

3. Sanitasi ruang tidur ABK pada KMP Legundi keseluruhan telah memenuhi syarat

4. Sanitasi air minum pada KMP Legundi keseluruhan telah memenuhi syarat kondisi air yang memenuhi persyaratan fisik

5. Sanitasi limbah cair pada KMP Legundi tidak memenuhi syarat, tidak adanya pengolahan limbah cair sebelum dibuang

6. Sanitasi limbah medis/padat pada KMP Legundi tidak memenuhi syarat, tidak adanya pemisahan sampah sesuai jenisnya.

7. Keberadaan vektor pada KMP Legundi keseluruhan telah memenuhi syarat, 2 ruangan (33\%) terlihatnya tanda keberadaan vektor dan 4 ruangan (67\%) tidak terlihat adanya keberadaan vektor

\section{SARAN}

1. Bagi Kantor Kesehatan Pelabuhan Kelas 1 Surabaya

Diharapkan untuk tetap mempertahankan sistem pemeriksaan sanitasi kapal, serta diperlukannya pemantauan yang dilakukan secara berkala setiap 6 bulan sekali agar tidak menjadi tempat penyebaran 
penyakit. Serta memberi himbauan untuk melakukan pengolahan limbah cair yang dihasilkan dari kegiatan kapal sebelum dibuang, memberi himbauan kepada pemilik kapal maupun $A B K$ untuk selalu menjaga kebersihan kapal dan meningkatkan kuantitas maupun kualitas fasilitas agar penumpang menjadi nyaman.

2. Bagi Masyarakat

Diharapkan untuk masyarakat selalu menjaga kesehatan lingkungan sekitar dan kebersihan diri dalam penggunaan jasa kapal maupun dalam lingkungan pelabuhan agar tidak menjadi tempat perkembangbiakan maupun penularan penyakit.

\section{DAFTAR PUSTAKA}

Harahap, A. A. 2016. Hubungan Sanitasi Kapal dengan Kepadatan Kecoa pada Kapal Motor yang Sandar di Pelabuhan Tanjung Perak Surabaya. Jurnal Kesehatan Lingkungan. Surabaya : Departemen Kesehatan Lingkungan Fakultas Kesehatan Masyarakat Universitas Airlangga

IHR. 2005. International Health Regulation. Jakarta

Mutiarani, P. T. 2017. Studi Sanitasi Kapal Kargo dan Keberadaan Bakteri E.Coli pada Makanan Jadi di Wilayah Pelabuhan Tanjung Perk Surabaya. Jurnal Kesehatan Lingkungan. Surabaya : Departemen Kesehatan Lingkungan Fakultas Kesehatan Masyarakat Universitas Airlangga

Peraturan Menteri Kesehatan Republik Indonesia Nomor 416 tahun 1990 tentang syarat-syarat pengawasan kualitas air.

Peraturan Menteri Kesehatan Republik Indonesia Nomor 2348/MENKES/PER/IV/2011 tentang Organisasi dan Tata Kerja Kantor Kesehatan Pelabuhan. Jakarta: Ditjen PP-PL.

Peraturan Menteri Kesehatan Republik Indonesia Nomor 40 Tahun 2015 Tentang Sertifikat Sanitasi Kapal

Peraturan Menteri Kesehatan Republik Indonesia Nomor 492 Tahun 2010
Tentang Persyaratan Kualitas Air Minum

Peraturan Menteri Kesehatan Republik Indonesia Nomor 50 tahun 2017 tentang Standar Baku Mutu Kesehatan Lingkungan dan Persyaratan Kesehatan untuk Vektor dan Binatang Pembawa Penyakit serta Pengendaliannya.

Peraturan Menteri Negara Lingkungan Hidup Nomor 03 tahun 2007 tentang Fasilitas Pengumpulan dan Penyimpanan Limbah Bahan Berbahaya dan Beracun di Pelabuhan

Peraturan Menteri Perhubungan Republik Indonesia Nomor PM 39 tahun 2015 tentang Standar Pelayanan Penumpang Angkutan Penyebrangan.

Peraturan Menteri Perhubungan Republik Indonesia Nomor PM 61 Tahun 2019 Tentang Kelaiklautan Kapal Penumpang Kecepatan Tinggi Berbendera Indonesia

Peraturan Pemerintah Republik Indonesia Nomor 21 Tahun 2010 Tentang Perlindungan Lingkungan Maritim

Peraturan Pemerintah Republik Indonesia Nomor 7 Tahun 2000 Tentang Kepelautan

Lingkungan (PRL) Kantor Kesehatan Pelabuhan (KKP) Kelas I Makassar

Saifullah. 2010. Pengaruh Sanitasi dan Manajemen Kapal Terhadap Kepemilikan Sertifikat Sanitasi Kapal pada Pelabuhan Lhokseumaweh. USU e-journal. Medan: Pascasarjana Universitas Sumatera Utara.

Sanila, H. 2019. Hubungan Pengetahuan dan Lingkungan dengan Higiene Tempat Pengelolaan Makanan di Pelabuhan Tanjung Perak Surabaya. Medical Technology and Public Helth Journal. Surabaya : Universitas Nahdlatul Ulama Surabaya

Setiawan, D. 2019. Faktor-Faktor yang Berhubungan dengan Kondisi Sanitasi Kapal Penumpang di Pelabuhan Tanjung Perak Surabaya. Journal of University of Muhammadiyah Gresik. Gresik : Universitas Muhammadiyah Gresik 
Tawaddud, B. I. 2011. Studi Kondisi Tingkat Sanitasi pada Kapal Penumpang di Wilayah Kerja Kantor Kesehatan Pelabuhan (KKP) Kelas I Makassar Tahun 2011.
Makassar : Universitas Islam Negeri Alauddin Makassar

Undang-Undang Nomor 17 Tahun 2008 Tentang Pelayaran

Undang-Undang Nomor 6 Tahun 2018 Tentang Kekarantinaan Kesehatan 